\title{
Effect of Diffusion on Susceptibility to Cracking during Solidification
}

\author{
Jiangwei Liu ${ }^{\mathrm{a}}$ and Sindo Kou ${ }^{\mathrm{b}, *}$ \\ aSchool of Energy Science and Engineering, Central South University, \\ Changsha, 410083, China \\ ${ }^{b}$ Department of Materials Science and Engineering, The University of Wisconsin, \\ Madison, WI 53706, United States
}

\begin{abstract}
Cracking during solidification is a serious defect in welds and castings. A criterion for cracking that, unlike previous criteria/models, considers the grain boundary (where cracking occurs) was proposed recently. Based on this criterion, the maximum $\left|d T / d\left(f_{S}\right)^{1 / 2}\right|$ ( $T$ is temperature and $f_{S}$ fraction solid) of an alloy was proposed as an index for its crack susceptibility and the validity of the index was verified. The present study used the index to demonstrate the important effect of diffusion on the crack susceptibility and explained the surprisingly low crack susceptibility of Al-Mg alloys in welding. This was done by deriving closed-form equations to calculate the curves of crack susceptibility (the index) vs. solute content for binary $\mathrm{Al}-\mathrm{Si}, \mathrm{Al}-\mathrm{Cu}$ and $\mathrm{Al}-\mathrm{Mg}$ alloys. The curves were $\Lambda$-shaped, consistent with those observed in the crack susceptibility tests of binary alloy systems. It was shown that diffusion from liquid into Al-rich dendrites reduces the peak of the $\Lambda$-curve and shifts it to higher solute contents. The very high Mg solubility in solid $\mathrm{Al}, 17.5 \mathrm{wt} \%$ according to the $\mathrm{Al}-\mathrm{Mg}$ phase diagram, makes $\mathrm{Mg}$ diffusion unusually significant, thus explaining the good weldability of Al-Mg alloys. The present study indicates the need to consider diffusion when comparing $\Lambda$-curves of different alloy systems, where the phase diagram can affect diffusion, or different tests of the same alloy system, where the cooling rate during welding or casting can affect diffusion.
\end{abstract}

*Corresponding author. 


\section{Introduction}

Cracking of an alloy during solidification is a serious defect in welds and castings, called solidification cracking in the former [1] and hot tearing in the latter $[2,3]$. The prominent RDG model of Rappaz, Drezet and Gremaud [4] was the first hot tearing model with a physically sound basis. However, the grain boundary (GB), where cracking occurs, was not yet considered. As illustrated in Fig. 1, Kou [5] recently considered three factors along the GB between two neighboring columnar dendritic grains: 1. separation of grains from each other under tensile strain to cause cracking, 2. growth of grains toward each other to bridge together to resist cracking, and 3. liquid feeding along the GB to resist cracking. Based on the conservation of mass in a volume element at the GB near $\left(f_{S}\right)^{1 / 2}=1$, where cracking occurs, the following criterion for cracking during solidification was derived:

$$
\left\{\begin{array}{l}
\left.\frac{d \varepsilon_{\text {local }}}{d t}>\sqrt{1-\beta} \frac{d \sqrt{f_{S}}}{d T} \frac{d T}{d t}+\frac{d}{d z}\left[\left(1-\sqrt{1-\beta} \sqrt{f_{S}}\right) v_{z}\right]\right\}_{\sqrt{f_{S}} \rightarrow 1} \\
\text { (separation) (growth) }
\end{array}\right.
$$

where

Elocal: local tensile strain in the semisolid (mushy zone),

$t$ : time,

$\beta$ : solidification shrinkage,

$f_{S}$ : fraction solid during solidification,

$T:$ temperature,

$z$ : axial direction of columnar dendritic grains, and

$v z$ : velocity of liquid feeding along the GB. 
The LHS (left hand side) of Eq. (1) represents the local strain rate in the lateral direction of columnar dendritic grains to separate them from each other to cause cracking. The first term on the RHS (right hand side) represents the lateral growth rate of grains toward each other to bond together to resist cracking. The second term on the RHS of Eq. (1) represents the liquid feeding rate along the GB to resist cracking. Since $d\left(f_{S}\right)^{1 / 2} / d T$ and $d T / d t$ are both negative in value, the first term is positive. In fact, all three terms in Eq. (1) are positive. Cracking can occur if the LHS exceeds the RHS and if sites for crack initiation are available. These sites can be folded oxide films entrapped in the melt of an $\mathrm{Al}$ (or $\mathrm{Mg}$ ) alloy during melting and casting due to its very strong tendency to oxidize [3]. Folded oxide films in a casting melt or weld pool can act as sharp cracks during solidification. Micropores, too small to rise quickly and escape from the melt [6] may exist in the melt or coexist with folded oxide films [7]. The surfaces of castings or welds can also be crack initiation sites.

The higher the absolute value $\left|d T / d\left(f_{S}\right)^{1 / 2}\right|$, the smaller the growth term and hence the slower the growth rate are, that is, the less resistance to cracking. It was further shown that the higher $\left|d T / d\left(f_{S}\right)^{1 / 2}\right|$, the longer the liquid channel along the GB is, that is, the higher resistance to the liquid feeding that is needed to resist cracking. According to the Hagen-Poiseuille law [6], the volumetric flow rate of a liquid through a channel decreases with increasing channel length due to the resistance to flow caused by the viscosity of the liquid. Since cracking occurs during the terminal stage of solidification, that is, near $\left(f_{S}\right)^{1 / 2}=1,\left|d T / d\left(f_{S}\right)^{1 / 2}\right|$ near $\left(f_{S}\right)^{1 / 2}=1$ was proposed as a crack-susceptibility index [5]. The higher the index, the slower grains can grow to bridge together to 
resistance cracking and the more difficult it is for liquid to feed shrinkage to resist cracking.

The index, which is related to how the fraction solid $f_{S}$ varies with temperature $T$, depends on the alloy composition. Curves of $T v s .\left(f_{S}\right)^{1 / 2}$ were plotted for Al alloys based on their compositions using commercial thermodynamic software Pandat [8] and database PanAluminum [9] of CompuTherm and the Scheil solidification model [2], which assumes no diffusion in solid. The steepness of the slope of the $T-\left(f_{S}\right)^{1 / 2}$ curve is $\left|d T / d\left(f_{S}\right)^{1 / 2}\right|$. Since the steepness varies significantly especially near $\left(f_{S}\right)^{1 / 2}=1$, an average value $\left|\Delta T / \Delta\left(f_{S}\right)^{1 / 2}\right|$ was taken over the $\left(f_{S}\right)^{1 / 2}$ range of $(0.87)^{1 / 2}<\left(f_{S}\right)^{1 / 2}<(0.94)^{1 / 2}$ and $\Delta\left(f_{S}\right)^{1 / 2}$ is thus 0.0368 [5]. This range was selected to include the $\left(f_{S}\right)^{1 / 2}$ where the maximum $\left|d T / d\left(f_{S}\right)^{1 / 2}\right|$ occurs, but its upper and lower bounds were decided arbitrarily.

The crack susceptibility index was calculated based on $\left|\Delta T / \Delta\left(f_{S}\right)^{1 / 2}\right|$ for commercial Al casting alloys A206 and A356 and wrought alloy 2014 welded with filler metal 4145 Al. A206 was found more crack susceptible than A356 and filler metal 4145 Al was shown to reduce the crack susceptibility in welding $2014 \mathrm{Al}$, both consistent with results of crack susceptibility testing. The binary $\mathrm{Al}-\mathrm{Cu}$ alloy system was also studied. $\left|\Delta T / \Delta\left(f_{S}\right)^{1 / 2}\right|$ was plotted against the $\mathrm{Cu}$ content, and the crack susceptibility curve was $\Lambda$-shaped like those observed in crack susceptibility testing of binary alloy systems $[1,3]$. The peak of the crack susceptibility curve was at $3.5 \mathrm{wt} \% \mathrm{Cu}$, close to those at about 3.0 wt $\% \mathrm{Cu}$ reported by Pumphrey et al. [10] and Cross et al. [11]. However, when the $\left(f_{S}\right)^{1 / 2}$ range was changed to $(0.92)^{1 / 2}<\left(f_{S}\right)^{1 / 2}<(0.99)^{1 / 2}\left(\Delta\left(f_{S}\right)^{1 / 2}=0.0360\right)$, the peak of the $\Lambda$ curve changes to $1 \mathrm{wt} \% \mathrm{Cu}$, which was observed by Novikov et al. [12] and Spittle et al. 
[13]. These calculated results show the width and location of the $\left(f_{S}\right)^{1 / 2}$ range can be adjusted to change the $\Lambda$-curve and its peak, but there are no real justifications.

A new form of the same crack susceptibility index was adopted, that is, the maximum $\left|d T / d\left(f_{S}\right)^{1 / 2}\right|[14]$ instead of the average $\left|\Delta T / \Delta\left(f_{S}\right)^{1 / 2}\right|$ near $\left(f_{S}\right)^{1 / 2}=1[5]$. This new form of the index is consistent with the original one, which is $\left|d T / d\left(f_{S}\right)^{1 / 2}\right|$ near $\left(f_{S}\right)^{1 / 2}=1[5]$, because the maximum $\left|d T / d\left(f_{S}\right)^{1 / 2}\right|$ occurs near $\left(f_{S}\right)^{1 / 2}=1$. The maximum $\left|d T / d\left(f_{S}\right)^{1 / 2}\right|$ of an alloy or a weld was calculated based on its composition using Pandat [8], PanAluminum [9] and the Scheil solidification model (no diffusion), and several critical predictions were made and verified [14]. First, the filler metal that reduced the maximum $\left|d T / d\left(f_{S}\right)^{1 / 2}\right|$ of an alloy was shown to be the one that reduces its solidification cracking in welding, e.g., filler metal $4145 \mathrm{Al}$ for welding $2014 \mathrm{Al}$ and filler metal 4043 Al for welding $6061 \mathrm{Al}$. Second, the maximum $\left|d T / d\left(f_{S}\right)^{1 / 2}\right|$ increased in the order of $2014,2024,2219,6061$ and $7075 \mathrm{Al}$, identical to their ranking in crack susceptibility tests. Third, for each of the three binary alloy systems $\mathrm{Al}-\mathrm{Si}, \mathrm{Al}-\mathrm{Cu}$ and $\mathrm{Al}-\mathrm{Mg}$, the highest value of the maximum $\left|d T / d\left(f_{S}\right)^{1 / 2}\right|$ occurred at a composition close to the most susceptible composition in crack susceptibility tests. However, the predicted crack susceptibility of Al-Mg alloys was too high, higher than that of Al-Cu alloys, which is inconsistent with the better weldability of Al-Mg alloys.

The effect of diffusion on cracking during solidification is a fundamental subject, which to the best knowledge of the authors has not been understood. The present study was carried out to investigate this effect and to explain why Al-Mg alloys have good weldability. Al-Mg alloys have a very wide freezing temperature range, in which the 
semisolid material is vulnerable to cracking under tension induced by solidification shrinkage and thermal contraction.

\section{Analytical expression - no diffusion in solid}

Simple closed-form equations for the maximum $\left|d T / d\left(f_{S}\right)^{1 / 2}\right|$ will be derived here to predict the crack susceptibility. With the help of the phase diagrams alone, these equations can be used to predict the crack susceptibility of binary alloys. More importantly, they are very simple. The physical properties or parameters relevant to the crack susceptibility can be identified and how they affect it can be seen easily because they are shown explicitly in the equations. Computer models have been developed for studying cracking during solidification but they are often too complicated to use. Appreciation for analytical models or equations can be seen in the following quote [15]: "While substantial progress has been made to develop comprehensive models, it is realized that for the purposes of alloy design, these models are more complex than is often necessary. Evidence of this is that even now, researchers are still using the much simpler hot-tearing models, such as the Clyne-Davies model of hot tearing to explain many results, despite it being clear that it is unable to explain the hot-tearing response in many situations."

The closed-form equations will be derived for the maximum $\left|d T / d\left(f_{S}\right)^{1 / 2}\right|$. There are significant advantages in using the maximum $\left|d T / d\left(f_{S}\right)^{1 / 2}\right|$ as the index for the susceptibility to cracking during solidification. First, by just looking at the $T-\left(f_{S}\right)^{1 / 2}$ curve, the location of the maximum steepness $\left|d T / d\left(f_{S}\right)^{1 / 2}\right|$ in the curve can be identified easily. With $\left|\Delta T / \Delta\left(f_{S}\right)^{1 / 2}\right|$, however, the $\left(f_{S}\right)^{1 / 2}$ range has to be determined by trial and error until the calculated peak best fits the observed one. Second, unlike $\left|\Delta T / \Delta\left(f_{S}\right)^{1 / 2}\right|$, which is 
selected arbitrarily, the maximum $\left|d T / d\left(f_{S}\right)^{1 / 2}\right|$ of an alloy can be considered as a material property of the alloy. Third, unlike $\left|\Delta T / \Delta\left(f_{S}\right)^{1 / 2}\right|$ the maximum $\left|d T / d\left(f_{S}\right)^{1 / 2}\right|$ is mathematically well defined, thus allowing simple closed-form equations to be derived from it. Fourth, the option of including diffusion in the calculation of the solidification path, that is, $f_{S}(T)$, is currently unavailable in commercial thermodynamic software and databases, at least not in Pandat [8] and PanAluminum [9].

The most widely used equation to describe the fraction solid as a function of temperature, which is called the solidification path, is the equation derived by Gulliver [16] and Scheil [17], which is often called the Scheil equation [2]. This $f_{s}(T)$ equation can be written as follows [2]:

$f_{S}=1-\left(\frac{T_{m}-T}{T_{m}-T_{L}}\right)^{\frac{1}{k-1}}=1-\left(\frac{T_{m}-T}{-m_{L} C_{o}}\right)^{\frac{1}{k-1}}$

where

$f_{s}$ fraction solid,

$T_{m}$ : melting point of pure solvent,

$T$ : temperature,

$T_{L}$ : liquidus temperature,

$k$ : equilibrium segregation coefficient,

$m_{L}$ : slope of the liquidus line of the phase diagram, and

$C_{o}$ : solute content of the alloy before solidification.

The assumptions of the Scheil equation include: equilibrium at the interface between liquid and solid, complete diffusion in liquid, and no diffusion in solid. The liquidus line and the solidus line are assumed to be straight lines as an approximation, 
that is, $m_{L}$ and $k$ are both constant. Most Al alloys are eutectic on the Al-rich side of the binary Al-alloy phase diagram. The fraction of eutectic in the solidified alloy $f_{E}$ is the fraction of eutectic liquid $f_{L E}$ at the eutectic temperature $T_{E}$, that is, $f_{E}=f_{L E}=1-f_{S E}$. Thus, the Scheil equation becomes

$$
f_{E}=1-f_{S E}=\left(\frac{T_{m}-T_{E}}{-m_{L} C_{o}}\right)^{\frac{1}{k-1}}
$$

where $f_{S E}$ is the fraction solid at the eutectic temperature $T_{E}$.

Upon differentiating Eq. (1) with respect to $T$,

$$
\frac{d f_{S}}{d T}=-\left(\frac{1}{k-1}\right)\left(\frac{T_{m}-T}{T_{m}-T_{L}}\right)^{\frac{1}{k-1}-1}\left(\frac{-1}{T_{m}-T_{L}}\right)=\frac{1-f_{S}}{(k-1)\left(T_{m}-T\right)}
$$

Using the chain rule,

$$
\frac{d\left(\sqrt{f_{S}}\right)}{d T}=\frac{1}{2 \sqrt{f_{S}}} \frac{d f_{S}}{d T}=\frac{1}{2 \sqrt{f_{S}}} \frac{\left(1-f_{S}\right)}{(k-1)\left(T_{m}-T\right)}
$$

Since the steepness of a curve is the absolute value of the slope of the curve, the steepness of the curve of $T$ vs. $\left(f_{S}\right)^{1 / 2}$ can be expressed as follows:

$$
\left|\frac{d T}{d\left(\sqrt{f_{S}}\right)}\right|=\frac{2(1-k)\left(T_{m}-T\right) \sqrt{f_{S}}}{1-f_{S}}=\frac{2(1-k)\left(-m_{L}\right) C_{o} \sqrt{f_{S}}}{\left(1-f_{S}\right)^{2-k}}
$$

Eq. (5) is the closed-form equation for the index $\left|d T / d\left(f_{S}\right)^{1 / 2}\right|$ written in two different forms for convenience of discussion. The second form is obtained by substituting Eq. (1) into the first form.

According to Eq. [5], the steepness $\left|d T / d\left(f_{S}\right)^{1 / 2}\right|$ reaches its maximum at the eutectic temperature $T_{E}$, where the fraction solid is $f_{S E}$. As mentioned previously, $f_{E}=1-$ $f_{S E}$. Thus, the first form of Eq. (5) can also be written as follows: 


$$
\left|\frac{d T}{d\left(\sqrt{f_{S}}\right)}\right|_{a t\left(f_{S E}\right)^{-}}=\frac{2(1-k)\left(T_{m}-T_{E}\right) \sqrt{1-f_{E}}}{f_{E}}
$$

As can be seen subsequently, the curve of $T$ vs. $\left(f_{S}\right)^{1 / 2}$ according to the Scheil equation has an abrupt change in steepness at $f_{S E}$. At $\left(f_{S E}\right)^{-}$, the steepness is maximum and is given by Eq. (6). At $\left(f_{S E}\right)^{+}$, the steepness is minimum and is zero.

Eq. (6) shows $k,\left(T_{m}-T_{E}\right)$ and $f_{E}$ explicitly as key physical properties that affect the crack susceptibility. Thus, for an alloy system with a smaller equilibrium segregation coefficient $k$, wider maximum temperature range $\left(T_{m}-T_{E}\right)$ or smaller fraction eutectic $f_{E}$, the crack susceptibility index $\left|d T / d\left(f_{S}\right)^{1 / 2}\right|$ is higher. The decreasing crack susceptibility index $\left|d T / d\left(f_{S}\right)^{1 / 2}\right|$ with increasing fraction eutectic $f_{E}$ is consistent with the fact that more eutectic liquid at the roots of the columnar dendritic grains makes the grain boundary space at the roots more open and hence easier for liquid to reach and feed [3].

According to the Scheil equation shown by Eq. (2), for alloys with a very low solute content $C_{o}$ such as $0.1 \mathrm{wt} \%$, some liquid $\left(f_{E}\right)$ still remains, though very little, when the eutectic temperature $T_{E}$ is reached. Such alloys, like pure metals, are known to be resistant to cracking during solidification even though, according to Eq. (6), the maximum steepness is very high because of the very small $f_{E}$. This is because extensive bridging occurs at a point near $\left(f_{S}\right)^{1 / 2}=1$, where there is no longer enough liquid left to form continuous liquid films to separate grains. This point will be called $f_{S B}$, that is, the fraction solid at which extensive bridging occurs to end the crack susceptibility of the solidifying alloy. In the RDG model [4] the crack susceptibility was assumed to end at $f_{S}$ $=0.98$, that is, $f_{S B}=0.98$. In the model of Clyne and Davies [18], it was at $f_{S}=0.99$, that is, $f_{S B}=0.99$. Thus, $f_{S B}$ can be expected to be very close to 1.0 , but its exact value may 
vary slightly from alloy to alloy. For the purpose of discussion, however, it is assumed that $f_{S B}=0.98$, and hence $\left(f_{S B}\right)^{1 / 2}=0.99$.

Since extensive bridging occurs at $f_{S B}$ to end the crack susceptibility, beyond $f_{S B}$ the steepness $\left|d T / d\left(f_{S}\right)^{1 / 2}\right|$ is no longer relevant. Thus, if the steepness is still increasing beyond $f_{S B}$, the steepness at $f_{S B}$ is taken as the maximum steepness, which can be calculated by substituting $f_{S B}$ for $f_{S}$ in the second form of Eq. (5). If the maximum steepness occurs at $T_{E}$ before $f_{S B}$, it can be calculated by substituting $T_{E}$ for $T$ and $f_{S E}$ for $f_{S}$ in the first form of Eq. (5), where $f_{S E}$ can be calculated using Eq. (2).

Before leaving the discussion on $f_{S B}$, it is perhaps worth mentioning that in hot tearing models the crack susceptibility is often assumed to exist within a certain $f_{S}$ range, the upper bound of which is equivalent to $f_{S B}$. For instance, in the model of Clyne and Davies [18], the range of $0.90<f_{S}<0.99$ was assumed arbitrarily to be vulnerable to cracking. In fact, it was further assumed that stress relief occurs through mass and liquid feeding in $0.40<f_{S}<0.90$ and grain separation in $0.90<f_{S}<0.99$. The ratio $t_{V} / t_{R}$ was taken as the crack susceptibility, where $t_{V}$ is the vulnerable time period in $0.90<f_{S}<0.99$ and $t_{R}$ is the time available for stress relief in $0.40<f_{S}<0.90$.

\subsection{Binary Al-Si alloys}

The phase diagram of the binary Al-Si system is shown in Fig. 2a [19]. The liquidus line and the solidus line are both nearly perfect straight lines, indicating that $k$ and $m_{L}$ are both essentially constant, consistent with the assumptions of the Scheil equation. The $T-\left(f_{S}\right)^{1 / 2}$ curves in Fig. $2 \mathrm{~b}$ were calculated by substituting the physical properties of the Al-Si system in Table 1 into Eq. (1). The vertical dotted line indicates the onset of extensive bridging at $\left(f_{S B}\right)^{1 / 2}=0.99$. As $C_{o}$ decreases from 4 to about $0.4 \mathrm{wt} \%$ 
Si, the maximum steepness $\left|d T / d\left(f_{S}\right)^{1 / 2}\right|$, which occurs at $T_{E}$, increases. The $T-\left(f_{S}\right)^{1 / 2}$ curve of Al-0.4Si, if it was drawn, would intersect $T_{E}$ at the vertical line. Thus, the $T$ $\left(f_{S}\right)^{1 / 2}$ curve of $\mathrm{Al}-0.4 \mathrm{Si}$ can be expected to have the highest value of the maximum steepness. For Al-Si alloys with more than $0.4 \mathrm{wt} \% \mathrm{Si}$, the maximum steepness occurs at $T_{E}$ before $f_{S B}$. On the other hand, for Al-Si alloys with less than $0.4 \mathrm{wt} \% \mathrm{Si}$, the maximum steepness occurs at $\left(f_{S B}\right)^{1 / 2}=0.99$, beyond which the steepness is even higher but no longer relevant because extensive bridging has already occurred to bond grains firmly.

The maximum steepness $\left|d T / d\left(f_{S}\right)^{1 / 2}\right|$ was calculated by substituting the physical properties of the Al-Si system in Table 1 into Eq. (5). The calculated maximum steepness is plotted vs. the Si content in Fig. 2c. As shown, the crack susceptibility curve based on the maximum steepness exhibits the shape of the Greek letter " $\Lambda$ " as in crack susceptibility testing of binary alloys $[1,3]$. The peak is at $0.4 \mathrm{wt} \% \mathrm{Si}$, consistent with the $T-\left(f_{S}\right)^{1 / 2}$ curves in Fig. 1b. It is close to that reported by Pumphrey et al. [10], which is indicated by the arrow in the figure. With commercial thermodynamic software Pandat [8] and PanAluminum [9] and the Scheil solidification model (no solid-state diffusion), the peak crack susceptibility is also at $0.4 \mathrm{wt} \% \mathrm{Si}$ [14]. Since the liquidus line and the solidus line are both straight lines, this suggests the closed form equations are correct.

\subsection{Binary Al-Cu alloys}

The phase diagram of the binary Al-Cu system is shown in Fig. 3a. Again, the liquidus line and the solidus line are both nearly perfect straight lines, indicating that $k$ and $m_{L}$ are both essentially constant. The $T-\left(f_{S}\right)^{1 / 2}$ curves in Fig. $3 \mathrm{~b}$ were calculated by substituting the physical properties of the Al-Cu system in Table 1 into Eq. (1). As compared to the curves of Al-Si in Fig. 1b, these curves are steeper mainly because of the 
wider freezing temperature range of the $\mathrm{Al}-\mathrm{Cu}$ system. The maximum steepness $\left|d T / d\left(f_{S}\right)^{1 / 2}\right|$ was calculated by substituting the same physical properties into Eq. (5). The calculated crack susceptibility curve in Fig. $3 \mathrm{c}$ is again $\Lambda$-shaped as in the case of the Al-Si system in Fig. 2c but higher. The peak crack susceptibility is at $1.2 \mathrm{wt} \% \mathrm{Cu}$, consistent with the $T-\left(f_{S}\right)^{1 / 2}$ curves in Fig. $3 b$. This closest reported peak crack susceptibility, by Novikov et al. [12] and Spittle et al. [13], is at about $1 \mathrm{wt} \% \mathrm{Cu}$ as indicated by the arrow in Fig. 3c. Similar peaks have been calculated based on no solidstate diffusion by several investigators. These include the peaks at $0.8 \mathrm{wt} \% \mathrm{Cu}$ calculated by Campbell and Clyne [20] using the model of Clyne and Davies [18], and $1.4 \mathrm{wt} \% \mathrm{Cu}$ by Rappaz et al. [4] using the RDG model and by Kou [14] using the maximum steepness $\left|d T / d\left(f_{S}\right)^{1 / 2}\right|$ along with Pandat [8] and PanAluminum [9].

\subsection{Binary Al-Mg alloys}

The Al-Mg binary phase diagram in Fig. 4a shows that the solidus line is not a straight line, that is, $k$ is not constant. The value of $k$ shown in Table 1 is based on the approximation that the solidus line is a straight line. This approximation is likely to cause errors in the $T$ - $\left(f_{S}\right)^{1 / 2}$ curves and the $\Lambda$-curve. However, the Al-Mg system is still included because Al-Mg alloys are widely used and because the effect of the Al-Mg phase diagram on the crack susceptibility can be demonstrated. As compared to Al-Si and Al-Cu, the AlMg phase diagram has a much lower eutectic temperature $T_{E}\left(450{ }^{\circ} \mathrm{C}\right)$ and a much higher maximum solubility of solute in solid $\mathrm{Al} C_{S M}(17.5 \mathrm{wt} \%)$.

The $T$ - $\left(f_{S}\right)^{1 / 2}$ curves in Fig. $4 \mathrm{~b}$ were calculated by substituting the physical properties of the Al-Mg system in Table 1 into Eq. (1). The curves are even steeper than those of the $\mathrm{Al}-\mathrm{Cu}$ system in Fig. $3 \mathrm{~b}$ mainly because of the even wider freezing 
temperature range caused by the very large difference of $210{ }^{\circ} \mathrm{C}$ between $T_{m}$ and $T_{E}$. The maximum steepness $\left|d T / d\left(f_{s}\right)^{1 / 2}\right|$ in Fig. 4c was calculated by substituting the same physical properties into Eq. (5). The crack susceptibility curve is even higher than that of the Al-Cu system in Fig. 3c. The two arrows indicate the peak susceptibility observed at about $2 \mathrm{wt} \% \mathrm{Mg}$ by Dowd et al. [21] and Cross et al. [11] and that at $5 \mathrm{wt} \% \mathrm{Mg}$ by Rosenberg et al. [22]. The dotted peak between the two arrows is where the calculated peak should have been located if the curved solidus line were considered by using Pandat [8] and PanAluminum [9] along with the Scheil solidification model [14].

The $\Lambda$-curve is significantly higher with the Al-Mg system (Fig. 4c) than the Al$\mathrm{Cu}$ system (Fig. 3c). This high crack susceptibility is due to the very steep $T-\left(f_{S}\right)^{1 / 2}$ curves (Fig. 4b) associated with the very wide freezing temperature range of Al-Mg alloys, which suggests a wide semisolid region vulnerable to cracking. Thus, Al-Mg alloys can be expected to be more crack susceptible than $\mathrm{Al}-\mathrm{Cu}$ alloys. However, the opposite is true according to the crack susceptibility tests of Cross et al. [11] and Rosenberg et al. [22]. This discrepancy will be discussed in the following section.

\section{Analytical expression - diffusion in solid}

According to Kurtz and Fisher [23], solid-state diffusion can be included in the $f_{S}(T)$ equation as follows:

$f_{S}=\frac{1}{1-2 \alpha^{\prime} k}\left[1-\left(\frac{T_{m}-T}{T_{m}-T_{L}}\right)^{\frac{1-2 \alpha^{\prime} k}{k-1}}\right]$

where

$$
\alpha^{\prime}=\alpha\left[1-\exp \left(-\frac{1}{\alpha}\right)\right]-\frac{1}{2} \exp \left(-\frac{1}{2 \alpha}\right)
$$


$\alpha=\frac{4 D_{S} t_{f}}{\lambda_{2}^{2}}$

$T_{L}:$ liquidus temperature,

Ds: diffusion coefficient of solute in solid dendrites,

$t_{f}$ : local freezing (solidification) time, and

$\lambda_{2}$ : secondary dendrite arm spacing.

As shown, $\alpha^{\prime}$ is a diffusion parameter related to the dimensionless solidification time $\alpha$ and hence the diffusion coefficient $D_{S}$, local solidification time $t_{f}$ and secondary dendrite arm spacing $\lambda_{2}$. For convenience of discussion, Eq. (8) is shown in the graphic form in Fig. 5. Without diffusion, $\alpha=\alpha^{\prime}=0$ and Eq. (7) reduces to Eq. (1), the Scheil equation. Eq. (9) shows that $\alpha$ (and hence $\alpha^{\prime}$ ) depends not only on the physical property $\left(D_{S}\right)$ of the alloy but also the solidification time $t_{f}$ and the secondary dendrite arm spacing $\lambda_{2}$, which in turn depend on the casting or welding conditions. The fraction of eutectic in the solidified material can be calculated from Eq. (7) as follows:

$$
f_{E}=1-f_{S E}=1-\frac{1}{1-2 \alpha^{\prime} k}\left[1-\left(\frac{T_{m}-T_{E}}{T_{m}-T_{L}}\right)^{\frac{1-2 \alpha^{\prime} k}{k-1}}\right]
$$

Eq. (7) can be rearranged as follows:

$$
T_{m}-T=\left(-m_{L}\right) C_{o}\left[1-\left(1-2 \alpha^{\prime} k\right) f_{S}\right]^{\frac{k-1}{1-2 \alpha^{\prime} k}}
$$

Upon differentiating Eq. (7) with respect to $T$,

$$
\frac{d f_{S}}{d T}=\left(\frac{-1}{1-2 \alpha^{\prime} k}\right)\left(\frac{1-2 \alpha^{\prime} k}{k-1}\right)\left(\frac{T_{m}-T}{T_{m}-T_{L}}\right)^{\frac{1-2 \alpha^{\prime} k}{k-1}-1}\left(\frac{-1}{T_{m}-T_{L}}\right)=\frac{-1+\left(1-2 \alpha^{\prime} k\right) f_{S}}{(1-k)\left(T_{m}-T\right)}
$$


By the chain rule,

$$
\frac{d\left(\sqrt{f_{S}}\right)}{d T}=\frac{1}{2 \sqrt{f_{S}}} \frac{d f_{S}}{d T}=\frac{1}{2 \sqrt{f_{S}}} \frac{-1+\left(1-2 \alpha^{\prime} k\right) f_{S}}{(1-k)\left(T_{m}-T\right)}
$$

Substituting Eq. (11) into Eq. (13),

$$
\left|\frac{d T}{d\left(\sqrt{f_{S}}\right)}\right|=\frac{2(1-k)\left(T_{m}-T\right) \sqrt{f_{S}}}{1-\left(1-2 \alpha^{\prime} k\right) f_{S}}=\frac{2(1-k)\left(-m_{L}\right) C_{o} \sqrt{f_{S}}}{1-\left(1-2 \alpha^{\prime} k\right) f_{S}}\left[1-\left(1-2 \alpha^{\prime} k\right) f_{S}\right]^{\frac{k-1}{1-2 \alpha^{\prime} k}}
$$

Eq. (14) shows $\alpha^{\prime}$ as a key parameter affecting the crack susceptibility. It shows the higher $\alpha^{\prime}$ is, the smaller $\left|d T / d\left(f_{S}\right)^{1 / 2}\right|$ and hence the crack susceptibility. In the extreme case of no solid-state diffusion, $\alpha=\alpha^{\prime}=0$ [23] and Eq. (14) reduces to Eq. (5), which was derived based on the Scheil equation, i.e., Eq. (1). In the extreme case of complete solid-state diffusion, on the other hand, $\alpha \rightarrow \infty$ and $\alpha^{\prime}=0.5$ [23]. Eq. (14) becomes an equation that follows the lever-arm rule for equilibrium solidification.

As shown by Eqs. (8) and (9), $\alpha$ and hence $\alpha^{\prime}$ are affected by the diffusion coefficient $D s$, local solidification time $t_{f}$ and secondary dendrite arm spacing $\lambda_{2}$. The diffusion coefficient $D_{S}$ is around $1 \times 10^{-12} \mathrm{~m}^{2} / \mathrm{s}$ for $\mathrm{Si}, \mathrm{Cu}$ and $\mathrm{Mg}$ in $\mathrm{Al}$ at $600^{\circ} \mathrm{C}$ [24]. As for the secondary dendrite arm spacing $\lambda_{2}$, numerous experimental data of Al alloys in both casting and welding show that it decreases with increasing cooling rate $[2,3]$. Minimizing the surface area and hence the surface energy of dendrites is the driving force for dendrite coarsening. The higher the cooling rate, the less time $t_{f}$ is available for coarsening to occur during solidification to increase $\lambda_{2}$. Fig. 9 shows $\lambda_{2}$ as a function of the cooling rate for some binary or essentially binary $\mathrm{Al}-\mathrm{Si}, \mathrm{Al}-\mathrm{Cu}$ and $\mathrm{Al}-\mathrm{Mg}$ alloys. The data were taken from casting of Al-9Si [25], casting of A356 (a casting alloy close to Al7Si) [26], directional solidification of Al-Cu alloys with 3.9 to $5.7 \mathrm{wt} \% \mathrm{Cu}$ [27], welding 
of $2014 \mathrm{Al}$ (a wrought alloy close to $\mathrm{Al}-4.4 \mathrm{Cu}$ ) [28] and casting of $5083 \mathrm{Al}$ (a wrought alloy close to Al-4.4Mg) [29].

The ranges of $\lambda_{2}$ likely to be found in Al welds and castings are also shown in Fig. 9. In welding of $\mathrm{Al}$ alloys the secondary dendrite arm spacing $\lambda_{2}$ can vary significantly with the welding process used. Within each welding process, $\lambda_{2}$ can further vary depending on the welding conditions used. Generally speaking, the higher heat input and lower travel speed, the larger $\lambda_{2}$ is $[1,28]$. Some example ranges from Al welding are as follows: about $2 \mu \mathrm{m}$ in laser- [30] or electron-beam welding [31], $5-20 \mu \mathrm{m}$ in gastungsten arc (also called TIG) welding [28], and $10-45 \mu \mathrm{m}$ in gas-metal arc (also called MIG) welding [32]. In casting, the melt is much larger in volume and hence solidifies much more slowly than the melt in a small weld pool during welding. Thus, $\lambda_{2}$ can be significantly larger in castings than in welds, for instance, from about 10 to over $100 \mu \mathrm{m}$ [2]. In general $\lambda_{2}$ in casting increases in the order of die casting, gravity-fed metal mold casting, sand casting and ingot casting.

Consider Al-Si alloys first. The $T-\left(f_{S}\right)^{1 / 2}$ curves in Fig. 6a were calculated at $\alpha^{\prime}=$ 0.2 using Eq. (7). As for the crack susceptibility curves in Fig. 6b, they were calculated with $\alpha^{\prime}$ ranging from 0 to 0.3 using Eq. (14). As can be seen by comparing Fig. 6a with Fig. $2 \mathrm{~b}$, diffusion causes the $T-\left(f_{S}\right)^{1 / 2}$ curves to become shallower, especially for alloys with less than $1 \mathrm{wt} \% \mathrm{Si}$. Thus, diffusion can be expected to reduce the crack susceptibility of these alloys. As shown in Fig. 6b, as diffusion increases the peak susceptibility is reduced and shifted toward higher Si contents.

Examples of welding and casting of Al-Si alloys are considered as follows. Cao and Kou [33] welded Al casting alloy A356 ( A1-7Si) by gas-metal arc welding using 
filler metal $4043 \mathrm{Al}(\sim \mathrm{Al}-5 \mathrm{Si})$, and the $\lambda_{2}$ was about $10 \mu \mathrm{m}\left(1 \times 10^{-5} \mathrm{~m}\right)$ in the resultant weld metal $(\sim \mathrm{Al}-6.3 \mathrm{Si})$. Filler metal $4047 \mathrm{Al}(\sim \mathrm{Al}-12 \mathrm{Si})$ was also used and the $\lambda_{2}$ was also about $10 \mu \mathrm{m}$ in the resultant weld metal ( Al-8.6Si). It should be mentioned that $\lambda_{2}$ tends to be finer along the weld centerline than the fusion boundary $[1,28]$. The average composition of the two welds is about Al-7.5Si. In both cases, a circular weld was made on a workpiece $102 \mathrm{~mm}$ by $102 \mathrm{~mm}$ by $3.2 \mathrm{~mm}$ with a $140 \mathrm{~A}$ current, $22 \mathrm{~V}$ voltage and $4.2 \mathrm{~mm} / \mathrm{s}$ travel speed. According to the Al-Si phase diagram in Fig. 2a, for Al-7.5Si the liquidus temperature $T_{L}$ is $614{ }^{\circ} \mathrm{C}$. Since $T_{E}=577^{\circ} \mathrm{C}$ (Table 1), the freezing temperature range $\left(T_{L}-T_{E}\right)$ is $37^{\circ} \mathrm{C}$. According to the data for Al-Si alloys in Fig. 9, the cooling rate is about $70{ }^{\circ} \mathrm{C} / \mathrm{s}$ at $\lambda_{2}=10 \mu \mathrm{m}$. Thus, the local solidification time $t_{f}$ is $0.53 \mathrm{~s}\left(=37^{\circ} \mathrm{C} / 70\right.$ $\left.{ }^{\circ} \mathrm{C} / \mathrm{s}\right)$. So, at $\lambda_{2}=10 \mu \mathrm{m}, \alpha=4 \times\left(1 \times 10^{-12} \mathrm{~m}^{2} / \mathrm{s}\right) \times(0.53 \mathrm{~s}) /\left(1 \times 10^{-5} \mathrm{~m}\right)^{2}=0.021$ according to Eq. (9). Based on $\alpha=0.021$ and Fig. 5, $\alpha^{\prime}=0.021$. As can be seen in Fig. 6b, as $\alpha^{\prime}$ increases from 0 to 0.025 (close to 0.021 ) the peak crack susceptibility drops from 7169 to $5471{ }^{\circ} \mathrm{C}$ and shifts from 0.42 to $0.51 \mathrm{wt} \% \mathrm{Si}$.

In casting Al-9Si alloy in a sand mold with a steel block positioned at one end of the mold to act as a chill to enhance cooling and improve the solidification microstructure. The finest dendritic structure was found near the chill as expected, where $\lambda_{2}$ was $32 \mu \mathrm{m}$ and the cooling rate based on Fig. 9 is $3{ }^{\circ} \mathrm{C} / \mathrm{s}$. From the Al-Si phase diagram in Fig. 2a, for Al-9Si the liquidus temperature $T_{L}$ is $604{ }^{\circ} \mathrm{C}$, and the freezing temperature range $\left(T_{L}-T_{E}\right)$ is $27^{\circ} \mathrm{C}(604-577=27)$. So, the local solidification time $t_{f}$ is $9 \mathrm{~s}\left(=27{ }^{\circ} \mathrm{C} / 3{ }^{\circ} \mathrm{C} / \mathrm{s}\right)$. Thus, $\alpha=4 \times\left(1 \times 10^{-12} \mathrm{~m}^{2} / \mathrm{s}\right) \times 9 \mathrm{~s} /\left(3.2 \times 10^{-5} \mathrm{~m}\right)^{2}=0.035$ according to Eq. (9). From Fig. 5, $\alpha^{\prime}=0.035$. As shown in Fig. 6b, as $\alpha^{\prime}$ increases from 0 
to 0.035 , which is about half way between 0.025 and 0.050 , the peak crack susceptibility drops from 7169 to $5044{ }^{\circ} \mathrm{C}$ and shifts from 0.42 to $0.55 \mathrm{wt} \% \mathrm{Si}$.

Consider Al-Cu alloys now. The $T-\left(f_{s}\right)^{1 / 2}$ curves in Fig. 7a were calculated at $\alpha^{\prime}=$ 0.2 using Eq. (7), and the crack susceptibility curves in Fig. 7b using Eq. (14), with $\alpha$ ' ranging from 0 to 0.3 . As can be seen by comparing Fig. $7 \mathrm{a}$ with Fig. $3 \mathrm{~b}$, the effect of diffusion is clear especially for alloys below $3 \mathrm{wt} \% \mathrm{Cu}$. It causes their $T-(f S)^{1 / 2}$ curves to become shallower, reducing their maximum steepness considerably. As shown in Fig. 7b, as diffusion increases the peak susceptibility is reduced and shifted toward higher $\mathrm{Cu}$ contents. This trend is clearer than that for Al-Si alloys.

In Fig. $7 \mathrm{~b}$ the peak at $3 \mathrm{wt} \% \mathrm{Cu}$ reported by Pumphrey et al. [10] and Cross et al. [11] and at $5 \mathrm{wt} \% \mathrm{Cu}$ by Rosenberg et al. [22] are now also included in order to show how widely the peak susceptibility can scatter in crack susceptibility testing. They were not shown in Fig. 3c in order to avoid distraction at that point of discussion. While more than one factor may contribute to scatter in the peak crack susceptibility, diffusion can certainly be one significant factor judging from Fig. 7b. Diffusion was likely significant in the study by Rosenberg et al. [22], where the use of sand molds for casting suggests a relatively low cooling rate. Other factors may also cause lower cooling rates in casting. For instance, mold preheating is known to reduce the cooling rate and hot tearing [34]. Unfortunately, details of the testing conditions are often not provided in the literature to allow better analysis of the data scatter. It is recommended that in future crack susceptibility tests the cooling rate and $\lambda_{2}$ also be reported.

Consider the following examples of welding and casting of $\mathrm{Al}-\mathrm{Cu}$ alloys. Lanzafame and Kattamis [28] welded 12.7 mm-thick $2014 \mathrm{Al}$ alloy ( $\mathrm{Al}-4.4 \mathrm{Cu})$ by gas- 
tungsten arc welding using filler metal 2319 Al $(\sim \mathrm{Al}-6.3 \mathrm{Cu})$. Under the welding conditions of $350 \mathrm{~A}$ current (which is high for gas-tungsten arc welding), $22 \mathrm{~V}$ voltage and $2.1 \mathrm{~mm} / \mathrm{s}$ travel speed, the $\lambda_{2}$ observed in the resultant weld was $22 \mu \mathrm{m}$. The cooling rate measured was $35{ }^{\circ} \mathrm{C} / \mathrm{s}$. The $\mathrm{Cu}$ content of the weld metal can be expected to be higher than $4.4 \mathrm{wt} \%$ (e.g., about $\mathrm{Al}-5 \mathrm{Cu}$ ) in view of the $\mathrm{Al}-6.3 \mathrm{Cu}$ filler metal used. According to the $\mathrm{Al}-\mathrm{Cu}$ phase diagram in Fig. $3 \mathrm{a}$, for $\mathrm{Al}-5 \mathrm{Cu}$ the liquidus temperature $T_{L}$ is $647{ }^{\circ} \mathrm{C}$. Since $T_{E}=548{ }^{\circ} \mathrm{C}$, the freezing temperature range $\left(T_{L}-T_{E}\right)$ is $99^{\circ} \mathrm{C}$. Based on the actually measured cooling rate of $35^{\circ} \mathrm{C} / \mathrm{s}$ (which is shown as a data point at $\lambda_{2}=22$ $\mu \mathrm{m}$ in Fig. 9), the local solidification time $t_{f}$ is $2.83 \mathrm{~s}\left(=99^{\circ} \mathrm{C} / 35^{\circ} \mathrm{C} / \mathrm{s}\right)$. So, at $\lambda_{2}=22$ $\mu \mathrm{m}, \alpha=4 \times\left(1 \times 10^{-12} \mathrm{~m}^{2} / \mathrm{s}\right) \times(2.83 \mathrm{~s}) /\left(2.2 \times 10^{-5} \mathrm{~m}\right)^{2}=0.023$ according to Eq. (9). Based on the $\alpha=0.023$ and Fig. 5, $\alpha^{\prime}=0.023$. As can be seen in Fig. 7b, as $\alpha^{\prime}$ increases from 0 to 0.025 (which is close to 0.023 ) the peak crack susceptibility drops from 9217 to $6500{ }^{\circ} \mathrm{C}$ and shifts from 1.3 to $1.7 \mathrm{wt} \% \mathrm{Cu}$.

Young et al. [35] solidified Al-4.4Cu alloy directionally. The local solidification time $t_{f}$ was $8 \mathrm{~s}$ at a location in the solidified material where $\lambda_{2}$ was $30 \mu \mathrm{m}$. From the Al-Cu phase diagram in Fig. 2a, for $\mathrm{Al}-4.4 \mathrm{Cu}$ the liquidus temperature $T_{L}$ is $650{ }^{\circ} \mathrm{C}$, and the freezing temperature range $\left(T_{L}-T_{E}\right)$ is $102{ }^{\circ} \mathrm{C}(650-548=102)$. Thus, $\alpha=4 \times\left(1 \times 10^{-12}\right.$ $\left.\mathrm{m}^{2} / \mathrm{s}\right) \times 8 \mathrm{~s} /\left(3 \times 10^{-5} \mathrm{~m}\right)^{2}=0.036$ according to Eq. (9). From Fig. $5, \alpha^{\prime}=0.036$. As shown in Fig. $7 \mathrm{~b}$, as $\alpha^{\prime}$ increases from 0 to 0.036 , which is half way between 0.025 and 0.050 , the peak crack susceptibility drops from 9217 to $5750^{\circ} \mathrm{C}$ and shifts from 1.3 to 1.8 $\mathrm{wt} \% \mathrm{Cu}$.

As for Al-Mg alloys, the $T-\left(f_{s}\right)^{1 / 2}$ curves in Fig. 8a were calculated at $\alpha^{\prime}=0.2$ using Eq. (7). Unlike the steep $T-\left(f_{S}\right)^{1 / 2}$ curves in Fig. $4 \mathrm{~b}$, these curves are nearly flat and 
show no eutectic. In the study of Cross et al. [11], Al-Mg alloys were found to contain little eutectic, much less than Al-Cu alloys and even less than Al-Si alloys. As for the crack susceptibility curves in Fig. 8b, they were calculated using Eq. (14) with $\alpha$ ' ranging from 0 to 0.3 . As diffusion increases, the peak susceptibility falls sharply and shifts to significantly higher $\mathrm{Mg}$ contents.

Examples of welding and casting of Al-Mg alloys are considered as follows. Goyal et al. [27] welded $5086 \mathrm{Al}$ alloy ( Al-4Mg) by pulsed gas-metal arc welding using filler metal $5183 \mathrm{Al}(\sim \mathrm{Al}-4.5 \mathrm{Mg})$ under various welding conditions, and the $\lambda_{2}$ in the resultant welds ranged from about 15 to $40 \mu \mathrm{m}$. Their cooling rate data seemed to deviate significantly from existing data the literature. Thus, Fig. 9 was still used to determine the cooling rate. According to the Al-Mg phase diagram in Fig. 4a, for Al-4Mg the liquidus temperature $T_{L}$ is $640{ }^{\circ} \mathrm{C}$. Since $T_{E}=450{ }^{\circ} \mathrm{C}$, the freezing temperature range $\left(T_{L}-T_{E}\right)$ is $190{ }^{\circ} \mathrm{C}(=640-450)$. According to the $5083 \mathrm{Al}$ data in Fig. 9 , for $\lambda_{2}=20 \mu \mathrm{m}$ the cooling rate is about $20{ }^{\circ} \mathrm{C} / \mathrm{s}$. Thus, the local solidification time $t_{f}$ is $9.5 \mathrm{~s}\left(=190{ }^{\circ} \mathrm{C} / 20^{\circ} \mathrm{C} / \mathrm{s}\right)$. So, at $\lambda_{2}=20 \mu \mathrm{m}, \alpha=4 \times\left(1 \times 10^{-12} \mathrm{~m}^{2} / \mathrm{s}\right) \times(9.5 \mathrm{~s}) /\left(2 \times 10^{-5} \mathrm{~m}\right)^{2}=0.095$ according to Eq. (9). Since $\alpha=0.095$, from Fig. $5, \alpha^{\prime}=0.092$. As can be seen in Fig. 8b, as $\alpha^{\prime}$ increases from 0 to 0.10 (close to 0.092 ) the peak crack susceptibility drops dramatically from 10823 to $1883{ }^{\circ} \mathrm{C}$ and shifts dramatically from 4.8 to $10.5 \mathrm{wt} \% \mathrm{Mg}$. As for casting, Easton et al. [32] cast $5083 \mathrm{Al}$ alloy at constant cooling rates ranging from 0.3 to $15{ }^{\circ} \mathrm{C} / \mathrm{s}$. The $\lambda_{2}$ in the resulting ingots ranged from about 20 to $80 \mu \mathrm{m}$. At $\lambda_{2}=20 \mu \mathrm{m} \mathrm{Mg}$ diffusion in the casting can be expected to be similar to that in the weld just discussed. It should be pointed out that when trying to determine $\alpha^{\prime}$ for a specific weld or casting by using its $\lambda_{2}$ and the $t_{f}$ (based on the $\lambda_{2}$ and Fig. 9), the freezing temperature range may be 
shortened to reduce $t_{f}$ if there is so much diffusion as to flatten the $T-\left(f_{S}\right)^{1 / 2}$ curves and eliminate the eutectic.

The Al-Mg phase diagram (Fig. 4a) shows a very high maximum solid solubility $C_{S M}(17.5 \mathrm{wt} \%)$ and a very low eutectic temperature $T_{E}\left(450{ }^{\circ} \mathrm{C}\right)$ far below the melting point $T_{m}\left(450^{\circ} \mathrm{C}\right)$. With a very high $C_{S M}$, much $\mathrm{Mg}$ in the interdendritic liquid can diffuse into the Al-rich dendrites. At any given temperature $T$ during solidification, the concentration of $\mathrm{Mg}$ in the interdendritic liquid is fixed as dictated by the phase diagram. In order to keep the $\mathrm{Mg}$ concentration of the liquid from dropping due to diffusion, the fraction solid $f_{S}$ has to increase significantly to reject more $\mathrm{Mg}$ into the liquid. Because the fraction solid $f_{S}$ at a given temperature $T$ increases significantly, the $T-\left(f_{S}\right)^{1 / 2}$ curves become much shallower (Fig. 8a).

The Al-Sn alloy system can be an interesting contrast of Al-Mg. The solubility of $\mathrm{Sn}$ in $\mathrm{Al}$ is negligible $\left(C_{S M} \sim 0\right)$ and the eutectic temperature is very low $\left(228^{\circ} \mathrm{C}\right)[19]$. The crack susceptibility of Al-Sn is very high, significantly higher than $\mathrm{Al}-\mathrm{Cu}$ and $\mathrm{Al}-\mathrm{Mg}$ as observed by Rosenberg et al. [22]. As they pointed out, since $C_{S M}$ is negligible, Sn cannot diffuse into the Al-rich dendrites during solidification. Thus, there is no chance at all for diffusion to help reduce the crack susceptibility. The liquidus line of the Al-Sn phase diagram is not a straight line. However, if Eq. (6) is used as an approximation, the crack susceptibility should be very high because $k$ is nearly zero, $T_{E}$ extremely low (= $\left.228^{\circ} \mathrm{C}\right)$ and $f_{E}$ very small due to the very low $k$ and $T_{E}$ according to Eq. (2).

Now return to the discussion on Al-Mg alloys. As can be seen by comparing Figs. 6, 7 and 8 , at the same $\alpha^{\prime}$ value (for instance, 0.025 ), that is, at the same $D_{S}, t_{f}$ and $\lambda_{2}$, the effect of diffusion on solidification cracking increases with increasing $C_{S M}$, from $1.6 \mathrm{wt} \%$ 
Si to $5.65 \mathrm{wt} \% \mathrm{Cu}$ to $17.5 \mathrm{wt} \% \mathrm{Mg}$. This explains why Al-Mg alloys can have relatively good weldability despite their very wide freezing temperature range. Thus, when explaining why one alloy is more crack susceptible than another, it is desirable to also check the maximum solid solubility.

\section{Conclusions}

1. Closed-form equations for calculating the susceptibility to cracking during solidification have been derived based on the maximum $\left|d T / d\left(f_{S}\right)^{1 / 2}\right|$ as the crack susceptibility index. This index, the validity of which has been verified in welding [14], is consistent with the recently proposed index of $\left|d T / d\left(f_{S}\right)^{1 / 2}\right|$ near $\left(f_{S}\right)^{1 / 2}=1$ [5] because the maximum $\left|d T / d\left(f_{S}\right)^{1 / 2}\right|$ occurs near $\left(f_{S}\right)^{1 / 2}=1$.

2. These simple equations are easy to use and can be useful tools for studying solidification cracking.

3. The crack susceptibility curves calculated for binary Al-Si, Al-Cu and Al-Mg alloys based on the index are $\Lambda$-shaped, consistent with those observed in the crack susceptibility tests of binary alloy systems.

4. The closed-form equation without diffusion, Eq. (6), shows that the crack susceptibility increases with decreasing equilibrium segregation coefficient $k$, increasing maximum temperature range $\left(T_{m}-T_{E}\right)$ or decreasing fraction eutectic $f_{E}$

5. The closed-form equation with diffusion, Eq. (14), shows that increasing $\alpha^{\prime}$, that is, increasing solute diffusion into dendrites during solidification, can significantly reduce the crack susceptibility, lowering the peak of the $\Lambda$-curve and shifting it toward higher solute contents. 
6. For the same alloy system diffusion is more likely to reduce the crack susceptibility significantly in a welding or casting process where the cooling rate is lower, e.g., gas-metal arc welding vs. gas-tungsten arc welding without filler metals, sand mold vs. metal mold, or preheated mold vs. room-temperature mold.

7. For different alloy systems the higher the maximum solid solubility $C_{S M}$, the more likely diffusion can reduce the crack susceptibility significantly. At a given $T, f_{S}$ must increase to reject more solute into the liquid to keep its solute content from falling due to solute loss caused by diffusion. This decreases $\left|d T / d\left(f_{S}\right)^{1 / 2}\right|$ and hence the crack susceptibility. Thus, diffusion can explain the good weldability of Al-Mg alloys despite their very large freezing temperature range.

8. When comparing, in welding or casting, the crack susceptibility curves of two different alloy systems or two different tests of the same alloy system, the effect of diffusion the crack susceptibility needs to be considered.

\section{Acknowledgements}

This work was supported by the National Science Foundation under Grant No. DMR 1500367. The coauthor Kou would like to dedicate this paper to his $\mathrm{PhD}$ advisor Merton C. Flemings, Emeritus Toyota Professor of MIT, Cambridge, MA, from whom he learned alloy solidification and transport phenomena and applied them to welding and casting. Flemings' early work with Rosenberg and Taylor on hot tearing of binary $\mathrm{Al}$ and Mg alloys [22] stimulated much new thinking during the course of the present study, particularly about the contrast between Al-Mg and Al-Sn. The coauthor Liu was supported by the China Scholarship Council as a visiting graduate student at the University of Wisconsin-Madison. 


\section{References}

[1] S. Kou, Welding Metallurgy, second ed., John Wiley and Sons, Hoboken, 2013, $257-300$.

[2] M.C. Flemings, Solidification Processing, McGraw-Hill, New York, 1974 (2526, Appendix).

[3] J. Campbell, Castings, second ed., Butterworth Heinemann, Oxford, 2003, 216247.

[4] M. Rappaz, J.M. Drezet, M. Gremaud, A new hot-tearing criterion, Metall. Mater. Trans. 30A (1999) 449-455.

[5] S. Kou, A criterion for cracking during solidification, Acta Mater. 88 (2015) 366374.

[6] S. Kou, Transport Phenomena and Materials Processing, John Wiley and Sons, Hoboken, 1996, 64-67.

[7] N. Coniglio and C. E. Cross, Mechanisms for solidification cracking initiation and growth in aluminum welding, Metall. Mater. Trans. A 40A (2009) 2718-2728.

[8] Pandat - Phase Diagram Calculation software package for Multicomponent Systems, Computherm LLC, Madison, WI 53719, 2001.

[9] PanAluminium - Thermodynamic database for Commercial Aluminum Alloys, Computherm LLC, Madison, WI 53719, 2001.

[10] W.I. Pumphrey, J.V. Lyons, Cracking during the casting and welding of the more common binary aluminium alloys, J. Inst. Metals 74 (1948) 439-455. 
[11] C.E. Cross, D.L. Olson, Hot tearing model to assess aluminum weldability, in Aluminum Alloys Their Physical and Mechanical Properties, vol. III, Conference Proceedings, Charlotsville, VA, 1986, pp. 1869-1875.

[12] I.I. Nivikov, Hot shortness of non-ferrous metals and alloys,_Russ. Cast. Prod. 4 (1962) 167-172.

[13] J.A. Spittle, A.A. Cushway, Influences of superheat and grain structure on hottearing susceptibilities of Al-Cu alloy castings, Metal Technol. 10 (1983) 6-13.

[14] S. Kou, A simple index for predicting the susceptibility to solidification cracking in welding, Welding Journal, accepted in July, 2015.

[15] M.A. Easton, M.A. Gibson, S. Zhu, and T.B. Abbott, An A priori hot-tearing indicator applied to die-cast Mg-rare earth alloys, Metall. Mater. Trans. A 45A (7) (2014) 3586-3595.

[16] G.H. Gulliver, Metallic Alloys (Appendix), Charles Griffin \& Co., Ltd., London, 1922.

[17] E. Scheil, Bemerkungen zur Schlichtkristallbildung, Z. Metallk., 34 (1942) 70.

[18] T.W. Clyne, G.J. Davies, Influence of composition on solidification cracking susceptibility in binary alloy systems, Br. Foundryman 74 (4) (1981) 65-73.

[19] American Society for Metals. 1986. Binary Alloy Phase Diagrams vol. 1: Metals Park, O.H., American Society for Metals.

[20] J. Campbell, T. W. Clyne, Hot tearing in Al-Cu alloys, Cast Metals 3(4) (1991) 224-226.

[21] J.D. Dowd, Weld cracking of aluminum alloys, Welding Journal 1952(31) $448 \mathrm{~s}-456 \mathrm{~s}$. 
[22] R.A. Rosenberg, M.C. Flemings, H.F. Taylor, Nonferrous binary alloys hot tearing, Trans. American Foundry Society, 68(1960) 518-528.

[23] W. Kurz and D.J. Fisher, Fundamentals of Solidification, $4^{\text {th }}$ ed., Trans Tech Publications, Aedermannsdorf, Switzerland, 1998, pp. 234-235.

[24] D.R. Poirier, G.H. Geiger, Transport Phenomena in Materials Processing, TMS Publications, Warrendale PA, 1994, p. 432.

[25] W.R. Osorio, P.R. Goulart, G.A. Santos, C.M. Neto, A. Garcia, Effect of dendritic arm spacing on mechanical properties and corrosion resistance of Al 9 wt pet Si and Zn 27 wt pct Al alloys, Metall. Mater. Trans. A, 37A (2006) 25252538.

[26] R.E. Spear, G.R. Gardner, Dendrite cell size, Trans AFS. 71 (1963) 209.

[27] D. Bouchard, J. Kirkaldy, Prediction of dendrite arm spacings in unsteady- and steady-state heat flow of unidirectional solidified binary alloys, Metall. Mater. Trans. B, 28B (1997) 651-663.

[28] J. N. Lanzafame and T. Z. Kattamis, Solidification structure and tensile properties of 2014 aluminum alloy, Welding Journal, 52 (1973) 226s-232s.

[29] M. Easton, C. Davidson, D. StJohn, Effect of composition on dendrite arm spacing of multicomponent aluminum alloys, Metall. Mater. Trans. A, 41A (2010) 1528-1538.

[30] A. Hirose, H. Tokada, K. F. Kobayashi, $\mathrm{CO}_{2}$ laser beam welding of 6061-T6 aluminum alloy thin plate, Metall. Mater. Trans. A, 28A (1997) 2657-2662.

[31] P. Wanjara, M. Brochu, Characterization of electron beam welded AA2024, Vacuum 80(2010) 268-282. 
[32] V. K. Goyal, P. K. Ghosh, J. S. Saini, Process-controlled microstructure and cast morphology of dendrite in pulsed-current gas-metal arc weld deposits of aluminum and Al-Mg alloy, Metall. Mater. Trans. A 38A (2007) 1794-1805.

[33] G. Cao, S. Kou, Liquation Cracking in Full-Penetration Al-Si Welds, Welding Journal, 84 (2005) 63s-71s.

[34] G. Cao and S. Kou, Real-time monitoring of hot tearing in AZ91E magnesium casting, Trans. American Foundry Society, 115(2007) paper 07-034.

[35] K.P. Young and D.H. Kirkwood, The dendrite arm spacings of aluminumcopper alloys solidified under steady-state conditions, Metall. Trans. A, 6A (1975) 197-205.

Table 1 Metallurgical properties of binary Al-Si, $\mathrm{Al}-\mathrm{Cu}$ and $\mathrm{Al}-\mathrm{Mg}$ alloy systems based on their phase diagrams.

\begin{tabular}{|l|l|l|l|l|l|l|}
\hline Alloy & $T_{m}$ & $T_{E}$ & $C_{E}$ & $C_{S M}$ & $k=C_{S M} / C_{E}$ & $-m_{L}=\left(T_{m}-T_{E}\right) / C_{E}$ \\
\hline Al-Si & $660^{\circ} \mathrm{C}$ & $577^{\circ} \mathrm{C}$ & 12.8 & 1.6 & 0.125 & $6.484^{\circ} \mathrm{C}$ \\
\hline Al-Cu & $660^{\circ} \mathrm{C}$ & $5488^{\circ} \mathrm{C}$ & 33.2 & 5.65 & 0.170 & $3.373{ }^{\circ} \mathrm{C}$ \\
\hline Al-Mg & $660^{\circ} \mathrm{C}$ & $450^{\circ} \mathrm{C}$ & 36.3 & 17.5 & 0.482 & $5.785^{\circ} \mathrm{C}$ \\
\hline
\end{tabular}




\section{Figure Captions}

Fig. 1 Factors affecting cracking during solidification, which occurs near end of solidification: 1. separation of grains from each other under tensile strain induced in casting or welding to cause cracking; 2. growth of grains toward each other to bridge together to resist cracking, and 3. liquid feeding along grain boundary to resist cracking. By considering the grain boundary, Kou [5] derived a criterion for cracking and showed increasing $\left|d T / d\left(f_{S}\right)^{1 / 2}\right|$ near $\left(f_{S}\right)^{1 / 2}=1$ reduces both factors 2 (bridging) and 3 (feeding).

Fig. 2 Al-Si alloy system: (a) Al-Si phase diagram [19]; (b) $T-\left(f_{S}\right)^{1 / 2}$ curves calculated by Eq. (1) with dotted line indicating $\left(f_{S}\right)^{1 / 2}=0.99$ at which extensive bridging is assumed to occur to end crack susceptibility; (c) crack susceptibility curve calculated by Eq. (5). Arrow in (c) indicates peak susceptibility at $0.7 \mathrm{wt} \% \mathrm{Si}$ observed by Pumphrey et al. [10].

Fig. 3 Al-Cu alloy system: (a) Al-Cu phase diagram [19]; (b) $T-\left(f_{S}\right)^{1 / 2}$ curves calculated by Eq. (1); (c) crack susceptibility curve calculated by Eq. (5). Arrow in (c) indicates peak susceptibility at about $1 \mathrm{wt} \% \mathrm{Cu}$ observed by Novikov et al. [12] and Spittle et al. [13].

Fig. 4 Al-Mg alloy system: (a) phase diagram [19]; (b) $T-\left(f_{S}\right)^{1 / 2}$ curves calculated by Eq. (1); (c) crack susceptibility curve calculated by Eq. (5). Arrow near $2 \mathrm{wt} \% \mathrm{Mg}$ indicates peak susceptibility observed by Dowd et al. [21] and Cross et al. [11] and that at $5 \mathrm{wt} \% \mathrm{Mg}$ by Rosenberg et al. [22]. Dotted peak, calculated using commercial software/database (without diffusion), indicates the peak location calculated based on 
the actual curved solidus line [14] instead of a straight one as an approximation required by Scheil equation.

Fig. 5 The diffusion parameter $\alpha^{\prime}$ in Eq. (9) shown as a function of $\alpha$ [23].

Fig. 6 Al-Si alloys: (a) $T$ - $\left(f_{s}\right)^{1 / 2}$ curves calculated by Eq. (7) with $\alpha^{\prime}=0.2$; (b) crack susceptibility curves by Eq. (14) with $\alpha$ ' ranging from 0 to 0.3 . Arrow in (b) is same as that in Fig. 2c.

Fig. 7 Al-Cu alloys: (a) $T-\left(f_{S}\right)^{1 / 2}$ curves calculated by Eq. (7) with $\alpha^{\prime}=0.2$; (b) crack susceptibility curves by Eq. (14) with $\alpha$ ' ranging from 0 to 0.3 . Arrows indicates peak susceptibility at about $1 \mathrm{wt} \% \mathrm{Cu}$ observed by Novikov et al. [12] and Spittle et al. [13], $3 \mathrm{wt} \% \mathrm{Cu}$ by Pumphrey et al. [10] and Cross et al. [11], and $5 \mathrm{wt} \% \mathrm{Cu}$ by Rosenberg et al. [22].

Fig. 8 Al-Mg alloys: (a) $T-\left(f_{S}\right)^{1 / 2}$ curves calculated by Eq. (7) with $\alpha^{\prime}=0.2$; (b) crack susceptibility curves calculated by Eq. (14) with $\alpha$ ' ranging from 0 to 0.30 . Dotted peak and arrows are same as those in Fig. 4c.

Fig. 9 Secondary dendrite arm spacing of binary or essentially binary $\mathrm{Al}-\mathrm{Si}, \mathrm{Al}-\mathrm{Cu}$ and Al-Mg alloys [25-29]. Example ranges of dendrite arm spacing in Al welding [28, 3033] and casting [2] are indicated by brackets. Ranges indicated by dotted lines are less often encountered. 
longitudinal crosssection

$\left(f_{S}\right)^{1 / 2}$ near 1

(1)

separating from each other under tensile strain
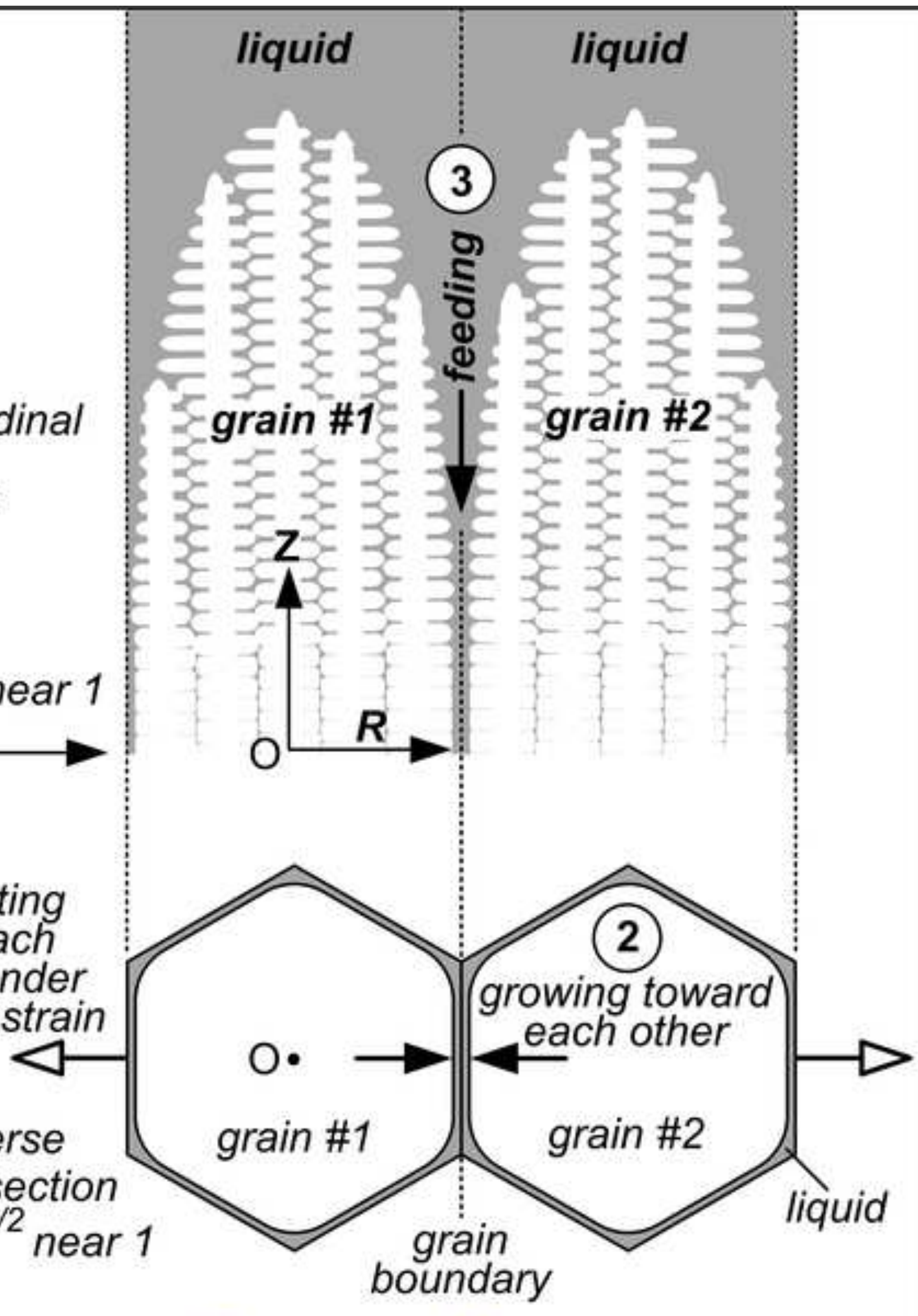

transverse cross-section at $\left(f_{S}\right)^{1 / 2}$ near 1

\section{grain boundary}

High $\left|d T / d\left(f_{S}\right)^{1 / 2}\right|$ near $\left(f_{S}\right)^{1 / 2}=1$ : inability to grow and bridge grains (2) and feed shrinkage (3) to resist cracking under tension induced by contraction during solidification (1). (Metals shrink upon solidification.) 


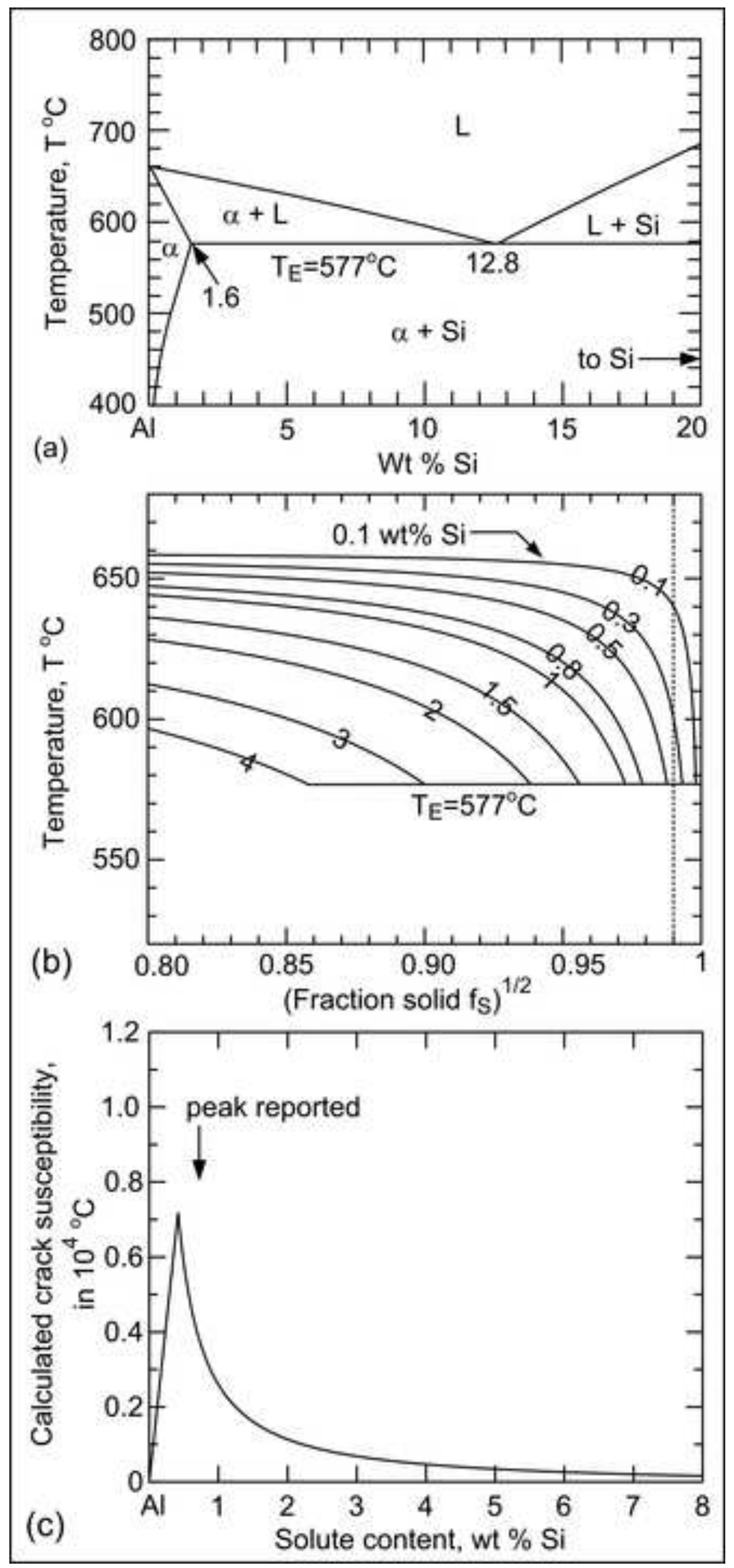




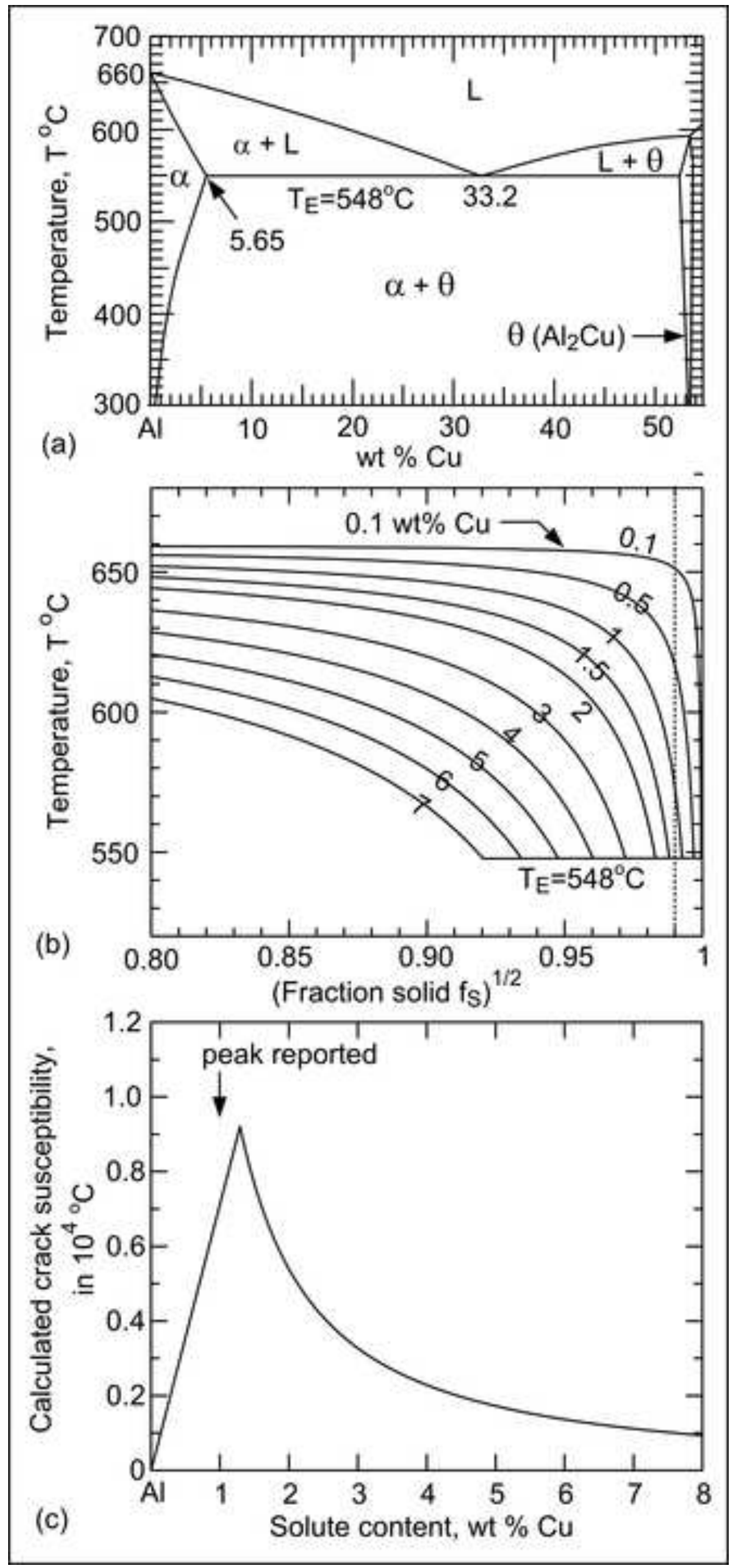




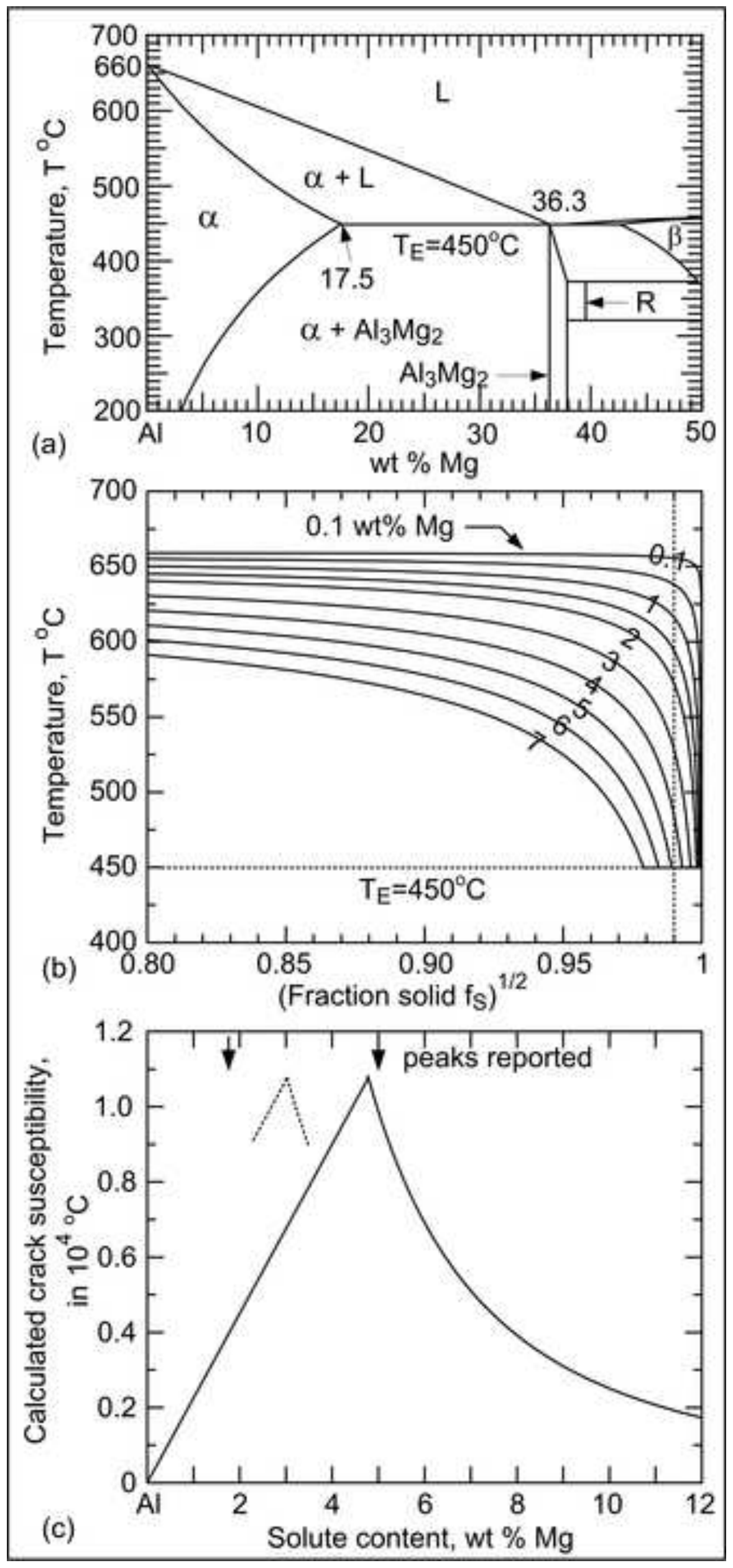




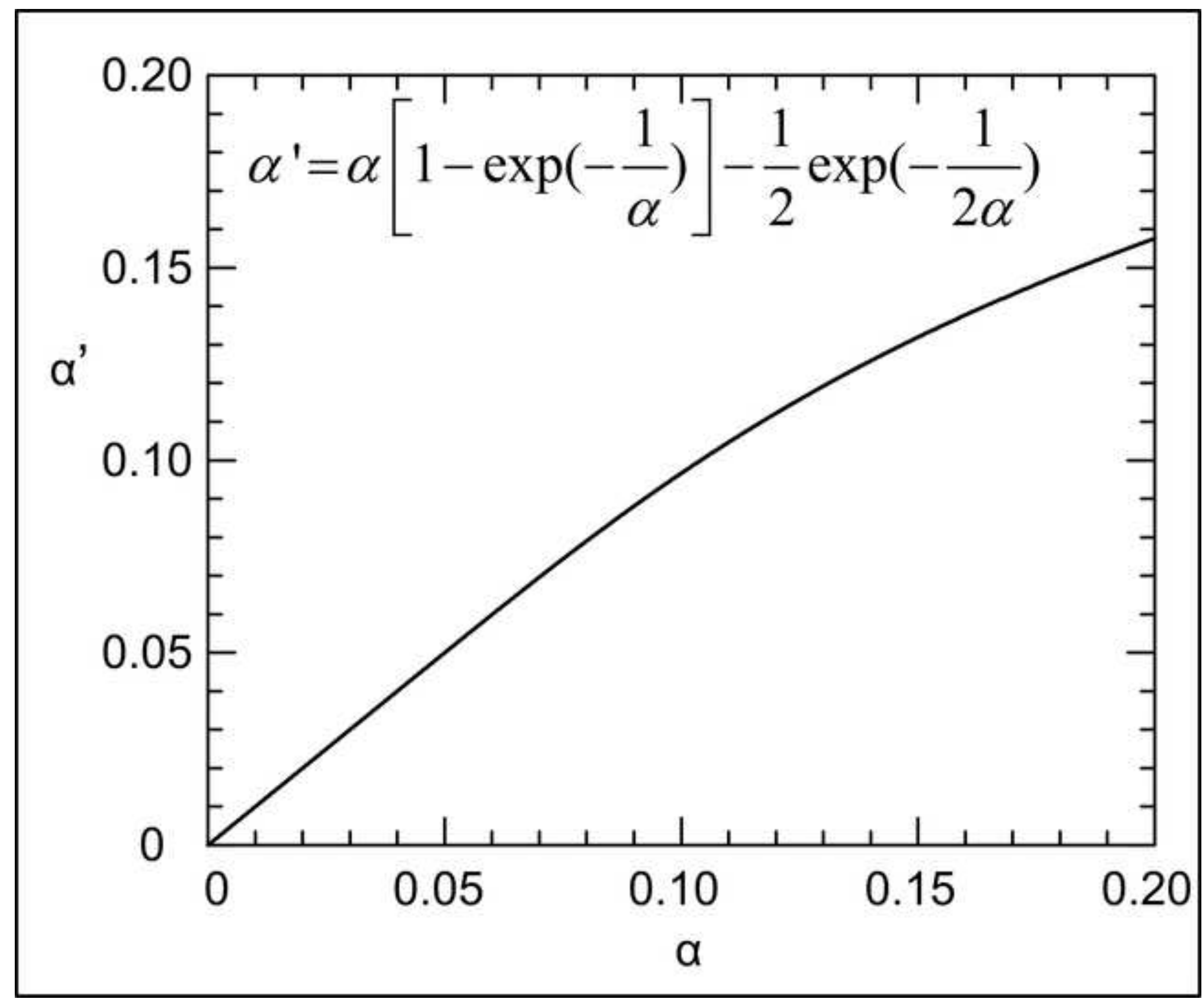




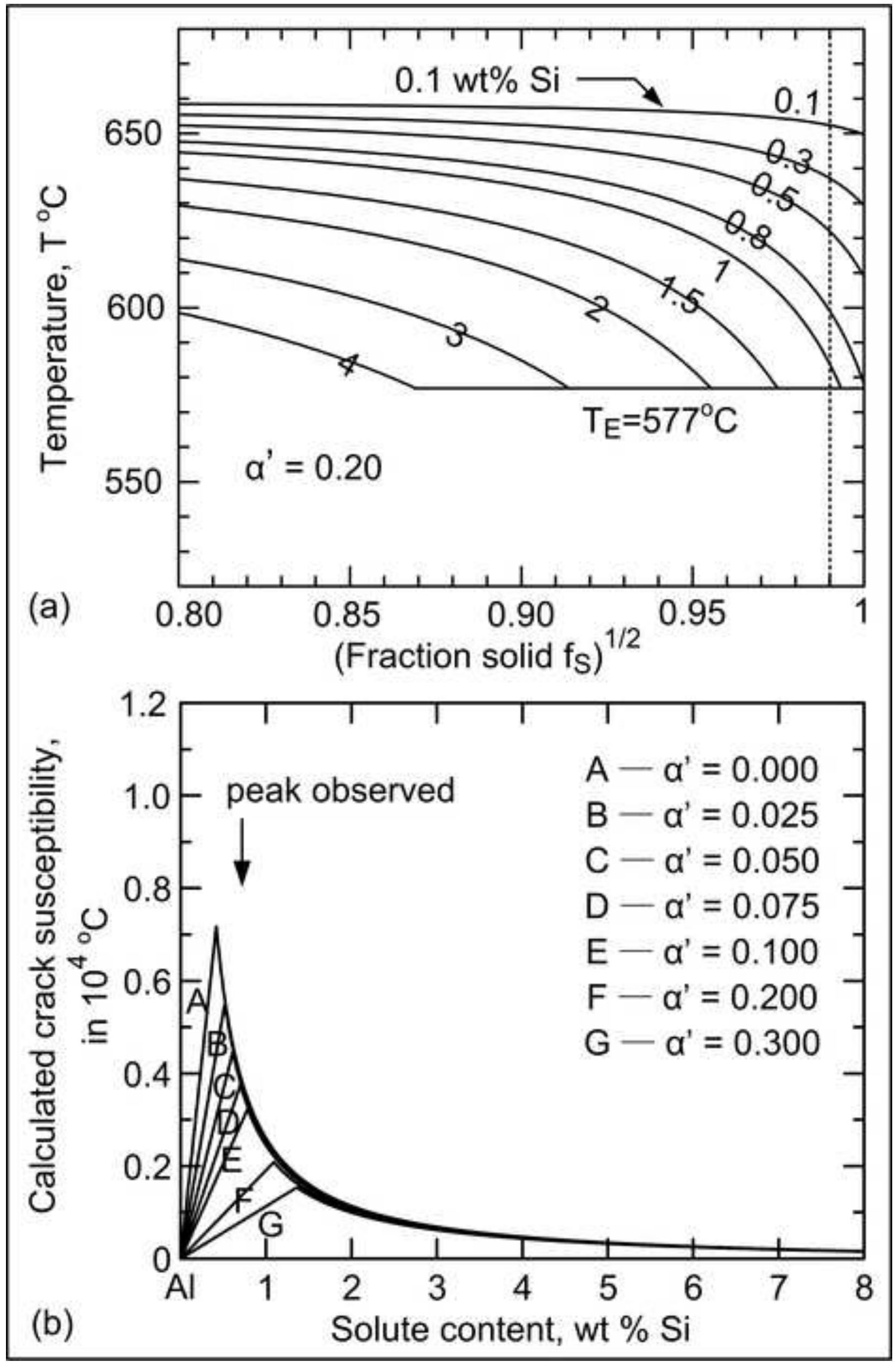




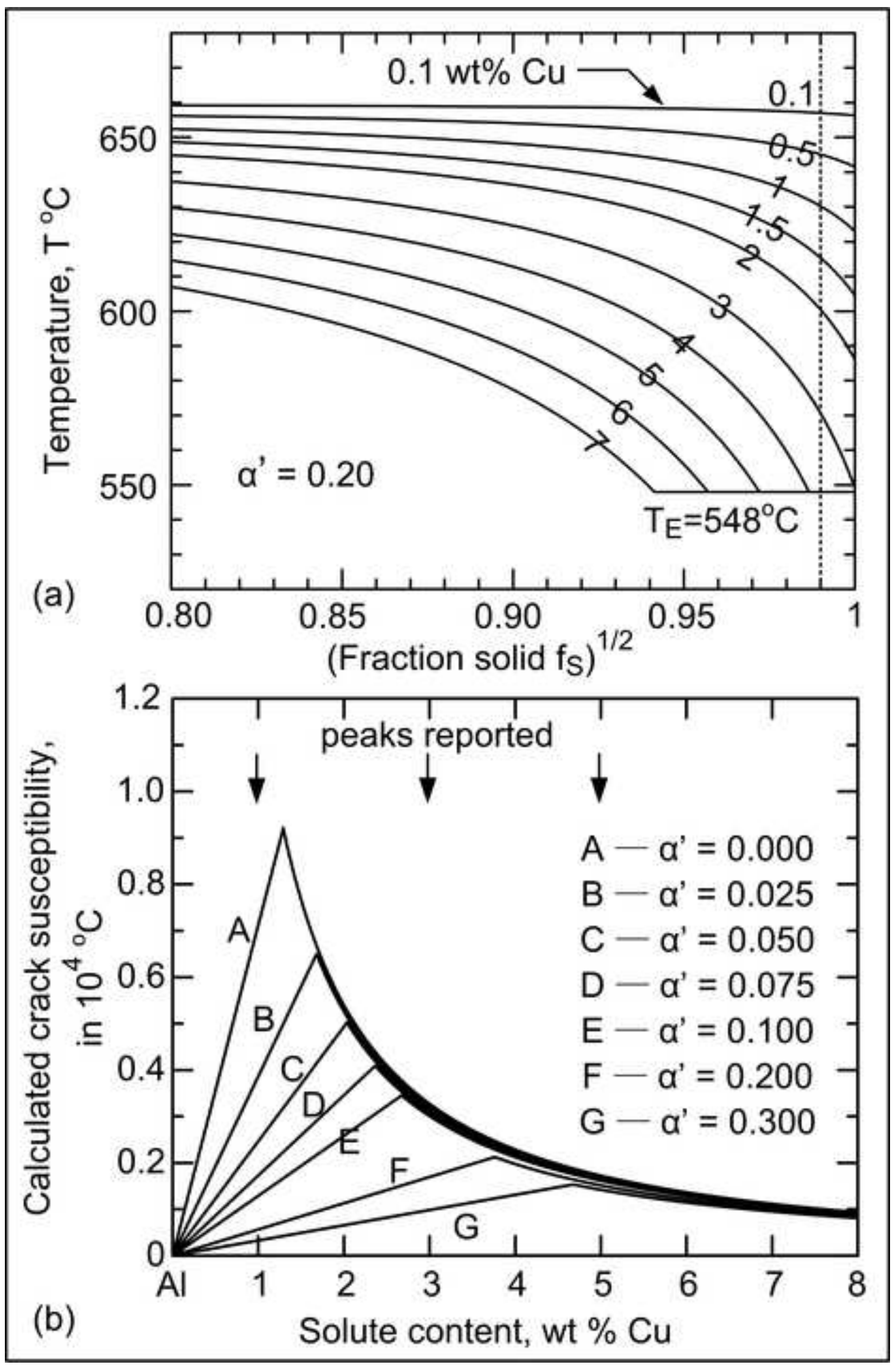




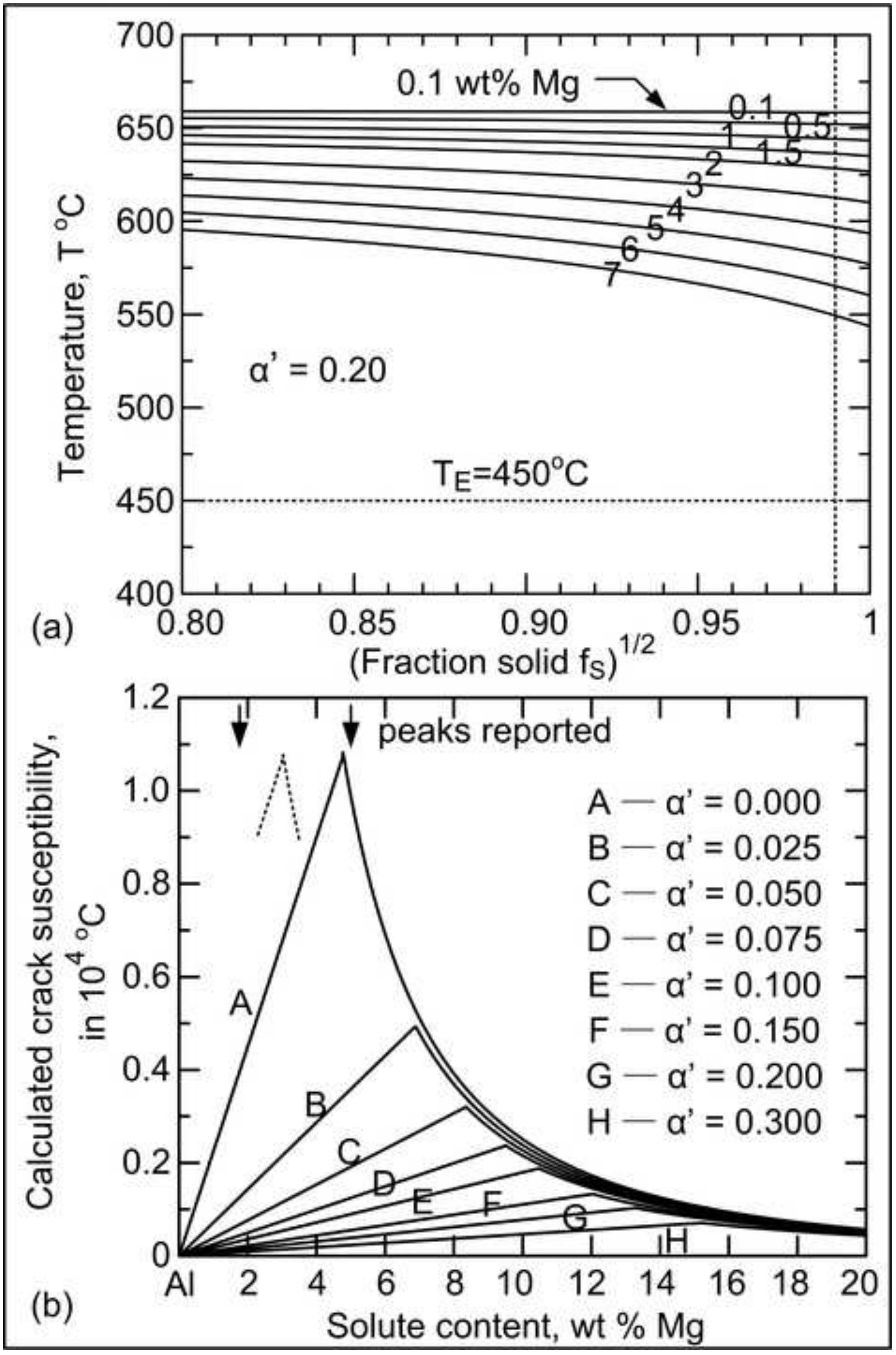




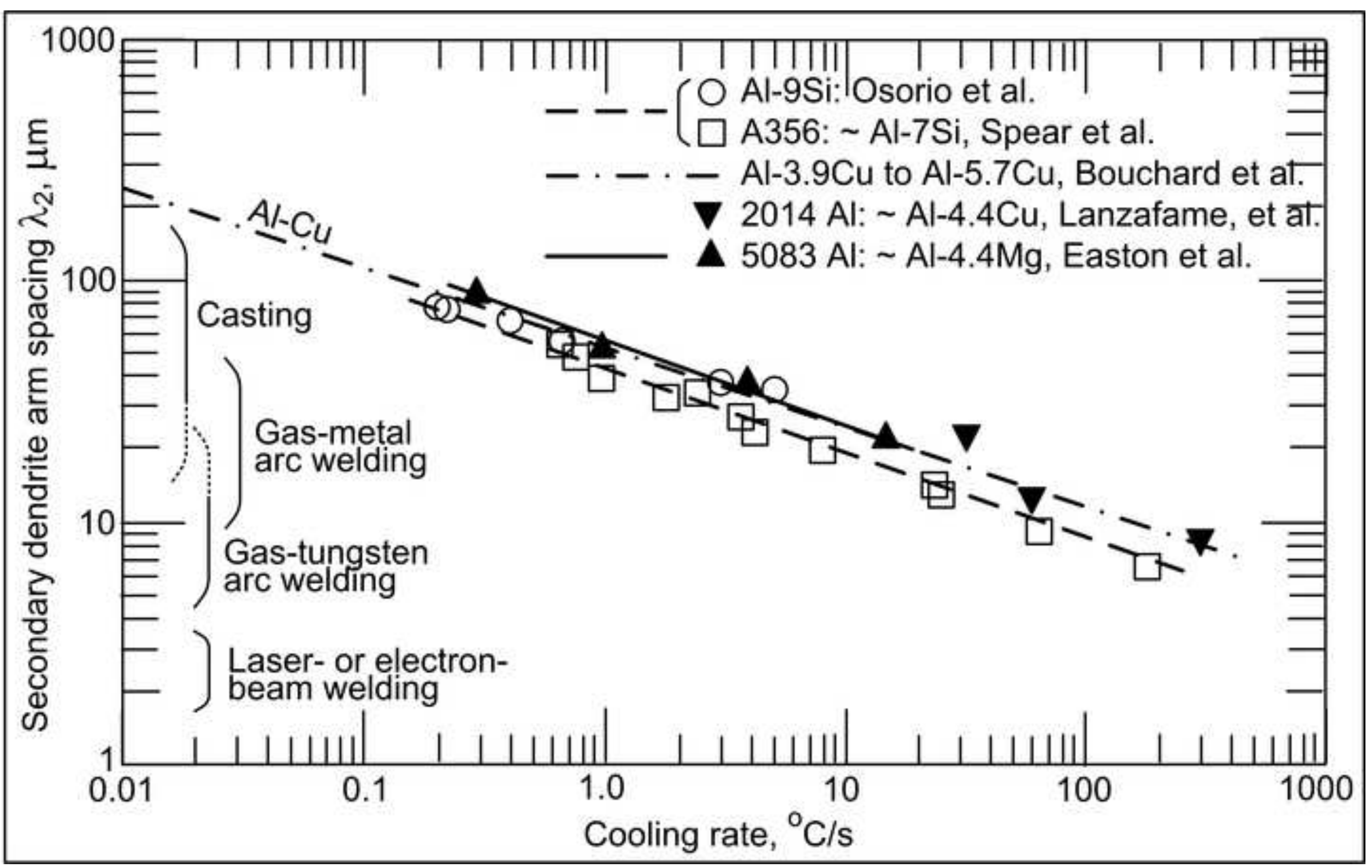




\section{Graphic Abstract}

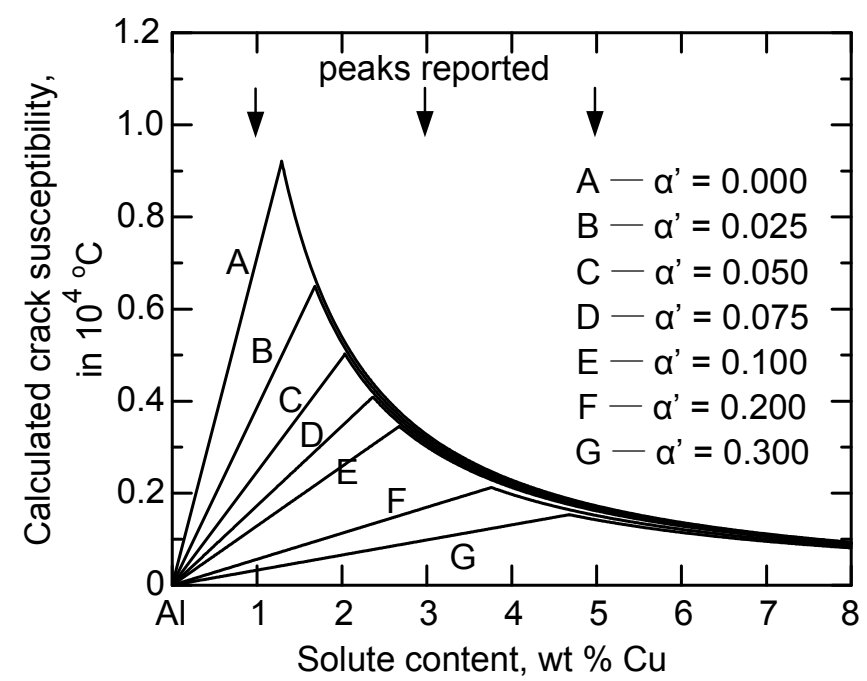

Cracking during solidification is a serious defect in castings and welds. This study showed that increasing solute (e.g., $\mathrm{Cu}$ ) diffusion into Al-rich dendrites (i.e., increasing diffusion parameter $\alpha^{\prime}$ ) can significantly reduce the peak of the crack susceptibility and shift it to higher solute contents. Differences in diffusion due to differences in the cooling rate during welding or casting may contribute to the wide scatter in the reported peak positions (indicated by arrows). This study also showed that diffusion is unusually high in Al-Mg alloys due to the very high (17.5 wt\%) $\mathrm{Mg}$ solubility in solid Al, which explains their low crack susceptibility despite their very wide freezing temperature range. 